PAEPRINT UCRL-78835

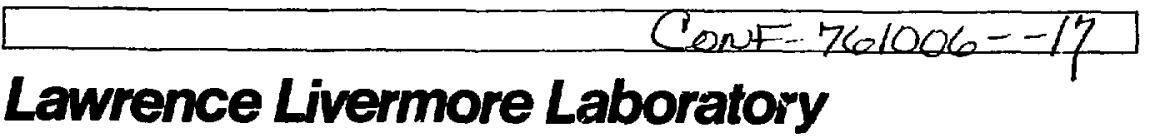

\title{
SUB-NANOSECOND PLASTIC SCINTILLATOR TIME RESPONSE STUDIES USING LASER PRODUCED X-RAY PULSED EXCITATION
}

K. G. Tirsell, G. R. Tripp, E. M. Lent, R. A. Lerche, J.C. Cheng - LLL

L. Hocker, EG\&G, Inc.,

P. B. Lyons, Los AIamos Ścientific Laboratory

November 17, 1976

WISTER

This paper was prepared for submission to

IEEE Transactions Nuclear Science Symposium

New Orleans, LA, October 11, 1976

This is a preprint of a paper intended for publication in a journal or proceedings. Since changes may be made before publication, this preprint is made available with the understanding that it will not be ciled or reproduced without the permission of the author.

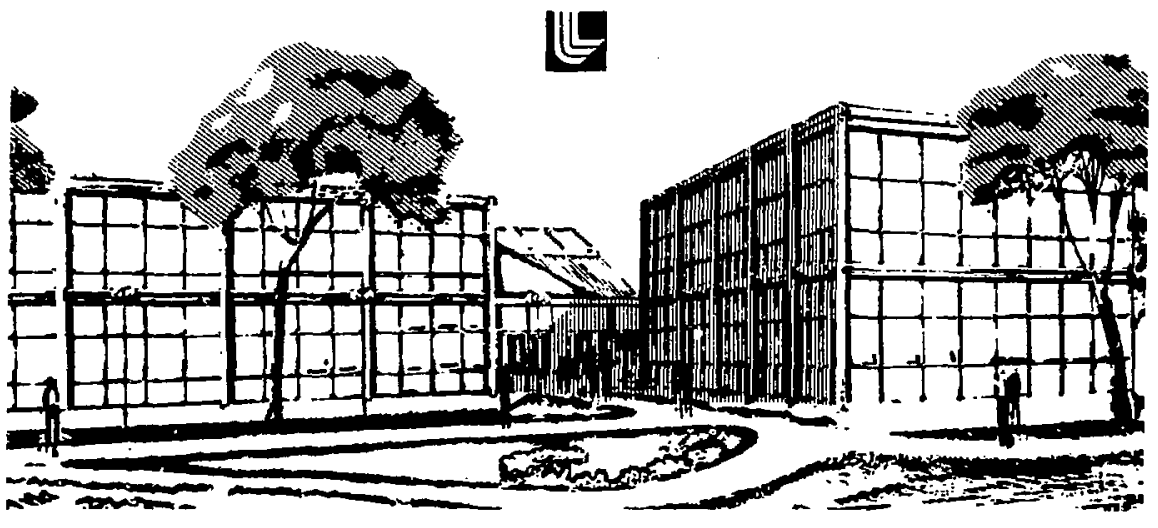


K. G. Tirsel1, G. R. Tripp, E. M. Lent, R. A. Lerche, and

J. C. Cheng, Lawrence Livermore Laboratory, L. Hocker,

EGSG, InC., and P. B. Lyons, Los Alanos Scientific Laburatory

\section{ABSTRACT}

The light emission time response of quenched NE11I plastic scintillators has been measured using a streak camera (20 ps resolution) and 100 to 180 ps, $1.06 \mu \mathrm{m}$. Iaser-produced, pulsed, low energy $x$-ray excitation. Each light output pulse was obtained by deconvolution from the film data using the $x$-ray temporal response measured with an $x$-ray sensitive streak camera (10 ps resolution). Time response parameters are presented for benzophenone and acetophenone, quenching zgents which most effectively reduce the decay time of the singlet component. Full width-haif-maximams $=260$ ps were observed for MEIII samples quenched with $\geq 2 \%$ benzophenone. Results are given for unquenched samples consisting of different concentrations of butyl-PBO in PVT and for the phosphor $\mathrm{ZnD}$ doped with Ga.

\section{INTROOUCTION}

Plastic scintillators are used in many types

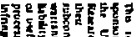

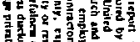

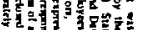
5

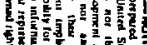

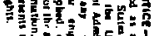

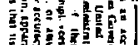

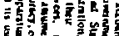

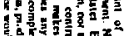

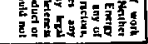

\section{of particle and photon detection systems to convert} the incident ionizing radiation to light. Extremely fast plastic scintillators are needed for many appliwill fill this need for those applications which do not require maximum sensitivity but which require superior time response. The development of these scin:illators and results of related measurements are presented in anozher paper. 1

\section{Because of time resolution limitations of} other methods, we have developed a streak camera technique for measuring fluor emission time respunse. cations such as plasma diagnostics. Quenched plastics Excitation is with single, laser-produced, low energy $x$-ray pulses. Since the basic resolution of the streak camera ${ }^{2}$ is 20 ps, the measurement is limited by the 100 to 180 ps FWH of the x-ray enission. However, by simultaneousily recording the $x$-ray enission response with an $x$-ray sensitive strea.. camera ${ }^{3}$, we are able to obtain the light output pulse by deconvolution. This technique provides better basic time resolution than other methods. For example, the single photoelectron method using fast photomultiplier tubes typically has 600 ps system resolution.

With low energy $x$-ray excitation, th in polished samples can be used and various geometrical effects can be greatly reduced, e.9., self absorption and reemission in the scintillator. Moreover, the Cerenkov background conponent observed in electron linac excitation is avoided.

A significant decrease in the decay time of the singlet state has been observed after quenching agents are added to the fastest commercial plastic, NEרIT (PBO (40mg/l) in a PVT matrix). ${ }^{4}$ Two of the most effective quenching agents include benzophenone and acetophenone. We have, therefore, chosen to study NE 111 quenched with these compounds in concentrations ranging from $1 / 2 \%$ to the onset of polymerization failure (approximately 15\%).

In addition, a group of plastics was studied to investigate the effect of varying buty?-PBD concentration in PVT. Butyl-PBO was chosen for its

* Work performed under the auspices of the U.S. Energy Researsh And Development Administration resemblance to $P B D$ and for its higher solubility. It was hoped that a faster time response would resuit from increased solute concentrations as was observed by Birks in his study of PBD in PYT. ${ }^{5}$

\section{EXPERIMENTAL PROCEDURE}

The $t$ erimental arrangement is shown in Fig. 1. A $1.067,1 \mathrm{~J}, 750$ ps laser pulse in focused on an ircn slab 2 : the center of an evacuated chamber. As the result of the plasma interaction, an $x$-ray pulse is produced with FWHM in the 120-180 ps range and a spectral sha's as shown in Fig. 2. (The $x$-ray energy distribut10. was measured with a 7-channel P-I-H diode array $w$, th appropriate K-edge filters.)

Two streak cameras are mounted symmetrically with respect to the laser beam and target to detect sinilar portions of the enitted $x$-ray pulse. Three plastic scintillator 5 mples ( 3 ma $\times 9 \mathrm{~m} \times 62 \mathrm{mon}$ ) were assembled in a 3-chanr.1 vacuun light guide $\beta$-shooter). $x$-rays transmitted thri igh a 25 pal Be light shield interact with the scint- llators. The light emitted from each is guided to - aparate sections of the photocathode of an UV sensit - 9 S-20 ul trafast streak camera. A light guide is 5 necessary to provide sufficient recordable liynt intensity. Material dispersion was avoided by using an evacuated guide with silvered walls for high refiectance in the fluor enission wavelength region ( $3800 \mathrm{~A}$ ). The three shooter permits more accurate neasurements of relative total light output because the three scintjllators sample a nearly identical portion of the $x$-ray pulse. A photographic view of the light guide, sample holder, mounted scintillators, and Be shield is shown in Fig. 3. The sides of the samples are blackened and each glass sample retaining well is coated to suppress internal sample reflections.

$x$-ray pulse shape infornation was recorded Ou. each shot to take into account variations in laser pulse duration. The $x$-ray streak camera was operated at approximately $40 \mathrm{ps} / \mathrm{mm}$ compared to $100 \mathrm{ps} / \mathrm{mm}$ for the optical streak camera.

\section{DATA ANALYSIS}

The scintillator raw data is a convolution of the fluor time response, the light guide time dispersion, and the input time response of the $x$-ray pulse. The light guide time dispersion is required to deconvoive the time response of the light emitted from the scintillatar. The $x$-ray time response is required to deconvolve the scintillator time response due to an instantaneous $x$-ray illput. The geners 1 data analysis procedure is outlined in Ffg. 4.

Typical raw data for both the $x$-ray streak canera and the 3 shooter are shown in Fig. 5 The raw film data is scanned by means of a micro-densitometer. Several scans are made to reduce the data noise level and are recorded on tape for computer processing. The step wedge technique is used to generate a $D-\log (E)$ filo calibration curve in order to obtain relative intensities from the film data. Results for a single scan are shown in Fig. 6 .

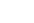


This data is corrected for the non-linear streak speed of exch cautera. The optical streak canera distance-time conversion curve was based on accurately known dimension: of an etalon. The etalon was used to develop a laser pulse train with a known puise separztion which was 'ad directly to the S-20 entrance slit. A laser-generated, double $x$-ray pulse was used to calibrate the $x$-ray streak camera. Additional data were obtained by using the x-ray stmeak camera deflection circuitry coupled to an optical streak camera of the same internal design and employing the standard optical camera calibration technique.

Relative intensities were corrected to account for the linear dependence of film exposure on the streak camera sweep velocity. An example of an $x$-ray time response thus derived is shown in $\mathrm{Fig} .7$. The calculated time dispersion of the light guide.

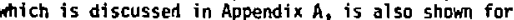
comparison.

As can be inferred from Fig. 7 the deconvo. lution is relatively insensitive to the uncertsinty in the light guide caiculation. Prior to the infolding aracedure the corrected scinthllator data was smoothed as shown in Fig. 8. A typical resultant time response is compared to the filtered input in Fig. 9.

\section{RESULTS}

The experimental results are summarized in Table 1. The time response measurements of the benzophenone quenched samples are shown in Fig. 10 . The 10\% to $90 \%$ rise times were roughly 100 os for a11 samples. Except for the total light output, the time response parameters for the buty1-PBD samples were remarkably consistent over a wide range of solute concentration. The time response of each sample in this group is faster than that of MElll. The lack of d trend for the time paraneters and the inconsistent values for total light emission suggest an uncertainty in the composition of the sample surfaces. (Note that the $x$-ray deposition occurs mainly in the first $30 \mathrm{tm}$ )

As shown in the table, the quenching effect of acetophenone is similar to that of benzophenone. We observe a decrease in the FWHM with increasing quencher concentration to a limiting value $=200$ ps The percentage of peak intensity measured 400 ns after the peak decreases monotonically as does the total light output of the benzophenone quenched samples.

The measured time response of $2 n 0$ phosphor coped with Ga was found to be independent of thickness. Averages were therefore tabulated. The FHAM values obtained for samples produced by westinghouse were all about 250 ps. The observed decay constant is also relativeiy short ( 340 ps). Nuclear Enterprise samples, possibly due to impurities, yielded a FWHI greater than 2 ns.

\section{OISCUSSION}

The observed 400 ps FWHM for each of the NE111 control samples is not in agreenent with values of $1.05 \mathrm{~ns}$ obtained using the electron linac. This does not appear to be due to problems with the streak camera technique. Tests with the laser have ruled out light transmission through the Be filter, a possible cause for a fast component. The streak speed calibration is considered good to within $10 \%$ on an absolute basis. The validity of the intensity correction is indicated by good agreenent between results obtained for shots differing greatly in raw data intensity.
Mast probably the disigreenent is due to differences in sanule excitation. High energy electrons excite the total sal. 'e volume. $X$-rays excite a thin surface layer, that part of the sample which is most susceptible to contamination.

Iistability or contamination of quenched plastic fluor surfaces may be a serious problem. Thus, a detailed comparison of measured light pulse shapes with theore$t$ ical models is not yet warranted.

\section{APPENOIX A}

\section{LIGHT GUIDE TRANSIT TIME DISPERSION CALCULATION}

The time dispersion of the light guide was calculated assuming uniform isotropic emission of light from the scintillator. Rays reflected from the silvered interior surfaces were traced from the scintillator to the strekk camera entrance slit over the 1 ight guide geometry in order to determine the distribution of path lengths. The dependence of the reflectance on the angle of illcidence was taken into account. ${ }^{6}$ Optical constants were used that have been measured for vacuum evaporated sllver with some exposure to air. 7 Preliminary calculations were made for a range of wavelengths covering the spectal emission region of NElil. He determined that results obtained for the MEIII peak emission wave-length (3800 A) would provide a good average. Calculations at these wavelengths were repeated using a large number of rays to obtain the results shown in Fig. 7 .

We wish to thank Dr. D. Attrood for the use of the Laser facility. We appreciate the advice and assistance of $\mathrm{Dr}$. R. Harding in the data reduction. Data analysis conputer programs developed by Dr. J. Heaver nere invaluable. We thank C. R. Hurlbut for his efforts in producing the scintillators.

\section{REFERENCES}

1. P. B. Lyons, S. E. Caldwell, L. P. Hocker, D. G. Crandal1, P. A. Zagarins, L. Franks, J. Cheng, G. Tirse11, and C. R. Hurlbut: Sub-Nanosecond Plastic Scintillators, submitted to the 1976 IEEE Nuclear Science Symposium.

2. S. W. Thomas, G. R. Tripp and L. W. Coleman, "Uitrafast Streaking Camera for Picosecond Laser Diagnostics", Proc. loth Int. Cong. on High Speed Photography, Assoc. Nationale de la Recherche Technique, Paris, 1972, pp. 127-133.

3. C. McConaghy and 1. Coleman, Applied Phystcs Letters 25: 268 (1974).

4. P. B. Lyons, C. R. Hurlbut and L. P. Hocker, Nuclear Inst. and Meth, 133, 175 (1976).

5. J. B. Birks and R. W. Pringle, Proc. Royal Soc. Edin. (R) 70, 233 (1971).

6. Georg Hass, "Mirror Coatings," in Applied Optics and Optical Engineering. Vol. 3, Rudolf Kingslake, Ed., (Academic Press, New York and London, 1965), pp. $309-330$

7. 9. H. Huebner, E. T. Arakawa, R. A. Machae, and R. N. Harm, Journal of the Optical Soc. of America. 541434 (1964). 
TABLE I

Heastred Time Responses of Scintillators to Pulsed Low Energy X-ray Radiation

\begin{tabular}{|c|c|c|c|c|c|}
\hline SCIRTILLATOR & $\mid \begin{array}{c}\text { Rise Time } \\
(10-90) \% \\
\text { ps }\end{array}$ & $\begin{array}{c}\text { FWHEN } \\
\text { pS }\end{array}$ & $\begin{array}{c}\text { Intensity } \\
\text { Peak }+ \\
900 \text { ps } q\end{array}$ & $\begin{array}{c}\text { Decay } \\
\text { Constan } \\
\text { ns }\end{array}$ & $\begin{array}{l}\text { Total } \\
\text { Light } \\
\text { Output }\end{array}$ \\
\hline PVT, Buty $1-P B D(50 \mathrm{~g} / \mathrm{\ell})$ & $110=25$ & $330 \pm 30$ & $33 \pm 5$ & $0.7 \pm 0.2$ & $(100)$ \\
\hline PVT, Butyl-PBO( $75 g / z)$ & $120: 40$ & $290 \pm 40$ & $35 \pm 4$ & $0.8=0.2$ & 32 \\
\hline PVT, Butyl-PBO(125g/2) & $110 \div 25$ & $260 \pm 50$ & $25 \div 5$ & $0.7 \pm 0.2$ & 69 \\
\hline PVT, Butyl-P80(1509/R) & $110 \div 40$ & $320=40$ & $30 \div 5$ & $0.7 \div 0.2$ & 27 \\
\hline PVT, Butyl-PBO(175g/ 2$)$ & $120=50$ & $280 \leq 40$ & $22 \div 5$ & $0.8 \pm 0.2$ & $\cdots$ \\
\hline PVT, Butyl-PBD $(200 \mathrm{~g} / \mathrm{\Omega})$ & $110=50$ & $360 \pm 60$ & $28 \div 4$ & $0.8 \pm 0.2$ & 56 \\
\hline NEIII & $100 \pm 25$ & $400 \pm 40$ & $38 \div 5$ & $0.7 \pm 0.3$ & $(100)$ \\
\hline NE1II + 5\% Acetophenore & $100 \pm 25$ & $230 \pm 30$ & $B \pm 3$ & $0.6 \pm 0.3$ & 2 \\
\hline NE111 + 158 Acetophenone & $90 \pm 25$ & $240 \pm 30$ & $<5$ & $0.5=0.3$ & 9 \\
\hline NE 11$]$ (control) & $110 \pm 30$ & $400 \pm 40$ & $35 \pm 5$ & $1.4 \pm 0.5$ & $(100)$ \\
\hline NE $111+0.5 \%$ Benzophenone & $110 \div 40$ & $360 \pm 60$ & $27 \pm 5$ & $0.7 \pm 0.3$ & 35 \\
\hline NEIII + 2\% Benzephenone & $100 \div 30$ & $260 \pm 40$ & $21 \pm 4$ & $0.7 \pm 0.3$ & 10 \\
\hline NE111 + 5\% Benzephenone & $110 \pm 40$ & $260 \pm 40$ & $B \pm 3$ & $0.7 \pm 0.3$ & 6 \\
\hline NE111 + T06 Benzophenone & $100 \div 30$ & $220 \div 30$ & $3 \pm 2$ & $>1.5$ & 6 \\
\hline HE111 + 15\% Benzophenone & $100 \pm 30$ & $230 \pm 40$ & $\begin{array}{l}2 \pm 3 \\
-1 \\
\end{array}$ & $>2.5$ & 4 \\
\hline $2 \mathrm{nO}(\mathrm{Ga})^{c}$ & $100 \pm 25$ & $250 \pm 25$ & $21 \div 6$ & $0.34 \pm 0.10$ & \\
\hline
\end{tabular}

a Percentage of peak intensity 400 ps after the peak.

G Total light output relative to that of the first sample in the group.

c Average of four samples ranging in thickness from $1 / 2$ to $6 \mathrm{mg} / \mathrm{cm})^{2}$.

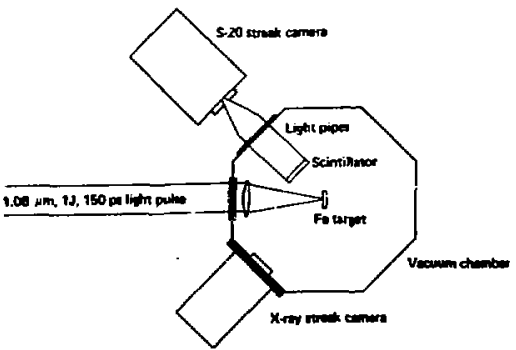

Fig. I. Experinental arrangervent used to measure scintiliator tine resporses. 


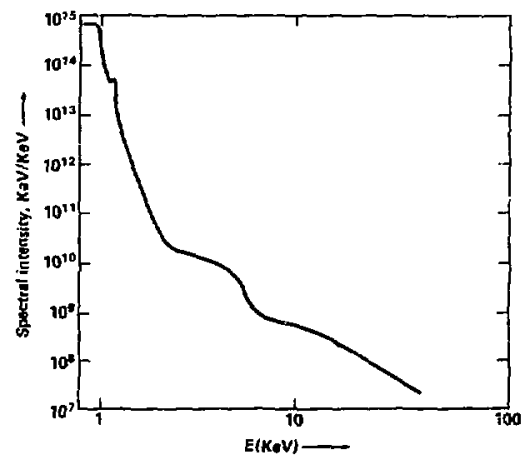

Fig. 2. Energy distribution of $x$-rays enitted from the iron slab target.

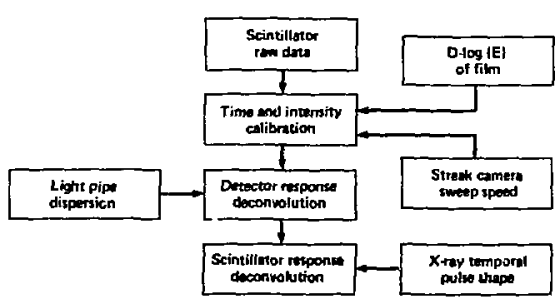

Fig. 4.. General data analysis procedure.

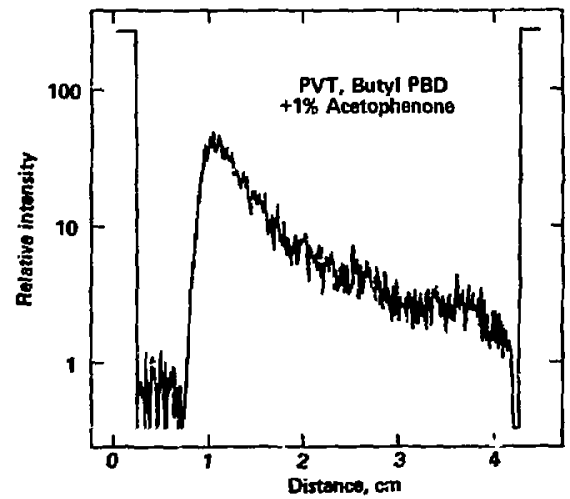

Fig. 6. Single micro-úensitometer scan of cile optica streak camera data. A step wedge generates $D-10 g(E)$ curve has been used to obtain relative intensity vs film distance.
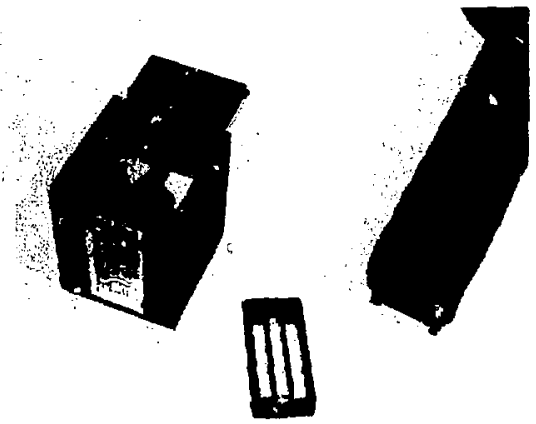

Fig. 3. View of the light guide, scintiliators, sample holder and Be light shteld.

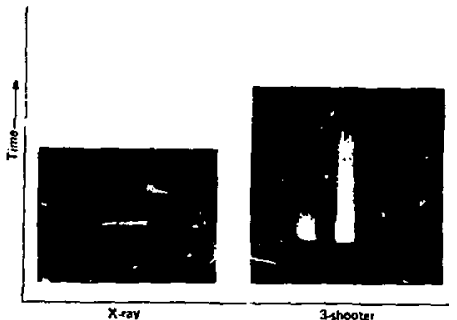

Fig. 5. Raw experimental film data for both the $x$-ray and optical streak cameras.

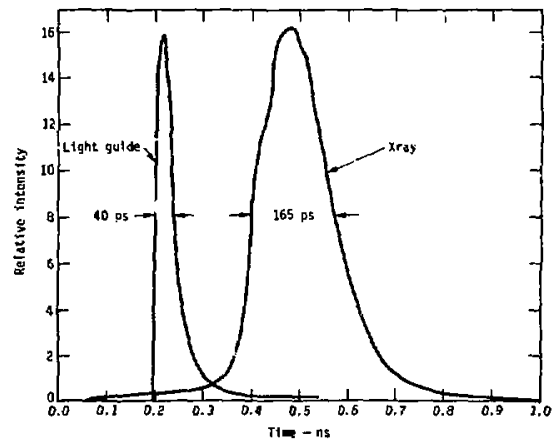

rig. 7. Typical measured $x$-ray time response compared to the calculated fluor emission transit time spread in the vacuum light guide. 


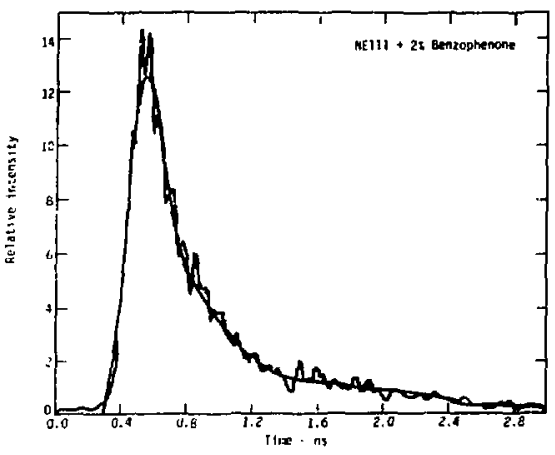

Fig. 8. Corrected scintłllator streak canera data before and after Fouritr smoothing.

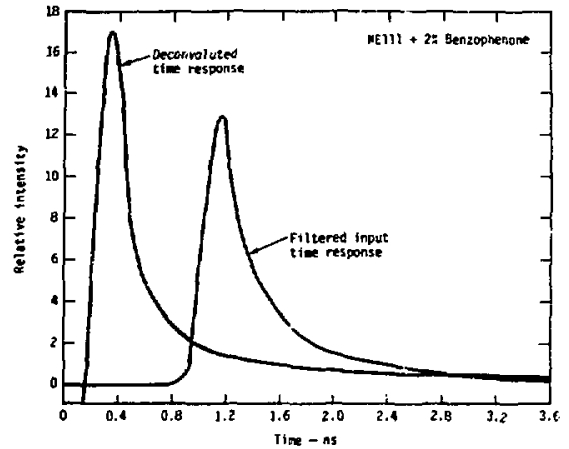

Fig. 9. A typical unfolded time response compared to the filtered input.
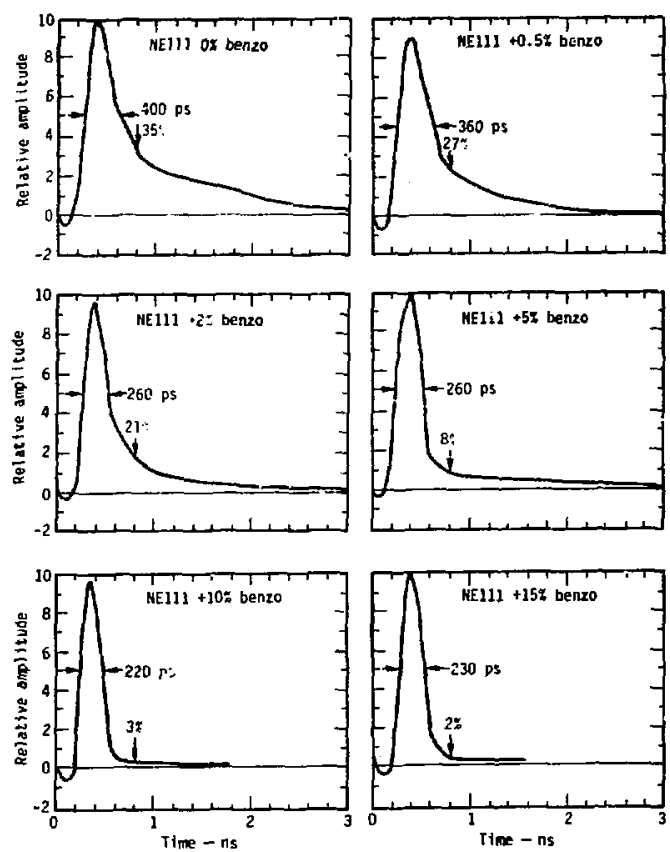

Fig. 10. Heasured time responses of MElll scirtillators to la energy $x$-ray excitation. Benzophenone quencher concentration ranges from 0 to $15 \%$. Initial regative excursions result from unfolding and are not real. 